\title{
Bilateral internal thoracic artery grafting: in situ or composite?
}

\author{
Hidetake Kawajiri, Juan B. Grau, Jacqueline H. Fortier, David Glineur \\ Department of Cardiac Surgery, Ottawa Heart Institute, Ottawa, Canada \\ Correspondence to: David Glineur. Department of Cardiac Surgery, Ottawa Heart Institute, Ottawa, Canada. Email: dglineur@ottawaheart.ca.
}

\begin{abstract}
Bilateral internal thoracic artery (BITA) grafting is considered a superior choice for coronary artery bypass grafting (CABG). While the 10-year outcomes of BITA grafting from the recent Arterial Revascularization Trial (ART) are still pending, numerous observational studies have demonstrated the advantages of BITA grafting. These include better long-term graft patency and freedom from arteriosclerosis, in addition to higher survival rate compared to CABG using only the left internal thoracic artery (ITA). The different BITA configurations are in situ and composite-the choice of optimal grafting configuration is challenging. Patient factors such as coronary anatomy, presence of a diseased ascending aorta and the potential need for a future redo sternotomy will influence the choice of the grafting strategy. In situ BITA grafting is associated with excellent clinical outcomes and has been extensively described in the literature. However, uncertainties remain regarding the ideal in situ configuration and design. Composite BITA grafting is the other option that maximizes right ITA (RITA) utilization. In this configuration, the RITA is able to reach the distal circumflex and right coronary artery branches. This approach decreases the need for a third graft conduit.
\end{abstract}

Keywords: Graft configuration; bilateral internal thoracic arteries (BITA); competition flow; coronary anatomy

Submitted Feb 03, 2018. Accepted for publication May 24, 2018.

doi: $10.21037 /$ acs.2018.05.16

View this article at: http://dx.doi.org/10.21037/acs.2018.05.16

\section{Introduction}

As the right internal thoracic artery (RITA) is anatomically and histologically similar to left ITA (LITA) with matching endothelial function (1) and RNA expression level (2), bilateral internal thoracic artery (BITA) grafting has become the reliable option in coronary artery surgery. Many observational studies have demonstrated the superiority of using BITA compared to single ITA for coronary artery bypass grafting (CABG) with respect to outcomes such as short-term and long-term graft patency and survival (3-5). Importantly, this superiority becomes more evident 10 years after the procedure in most series (6). Despite these positive data, the best configuration of BITA conduits during CABG remains a matter for debate. The aim of this review was to clarify the advantages and disadvantages of two BITA grafting methods (composite vs. in situ) and discuss basic principles of the revascularization using BITA.

\section{Technical considerations}

When comparing in situ versus composite ITA grafting, it is important to determine whether the grafts will be harvested in a skeletonized manner, and if a strategy of sequential grafting will be performed.

\section{Skeletonization of ITA}

The skeletonization harvesting technique is useful to increase graft length and optimize conduit utilisation. The use of skeletonized ITA has been described previously and demonstrates excellent safety and long-term patency $(7,8)$. Technically, skeletonization is often criticized for its longer harvesting time (9) and potential risk of damaging the ITA. It should be noted, however, that pathologic studies have not shown any endothelial damage when the ITA is adequately harvested either by electric cautery or by ultrasonic scalpel $(10,11)$. Some publications have reported longer harvesting times for skeletonized versus conventional, non-skeletonized conduits, but it can be completed in 25-30 minutes in most cases $(12,13)$.

With respect to graft length, Higami and colleagues (13) have described an ITA harvesting technique using the 

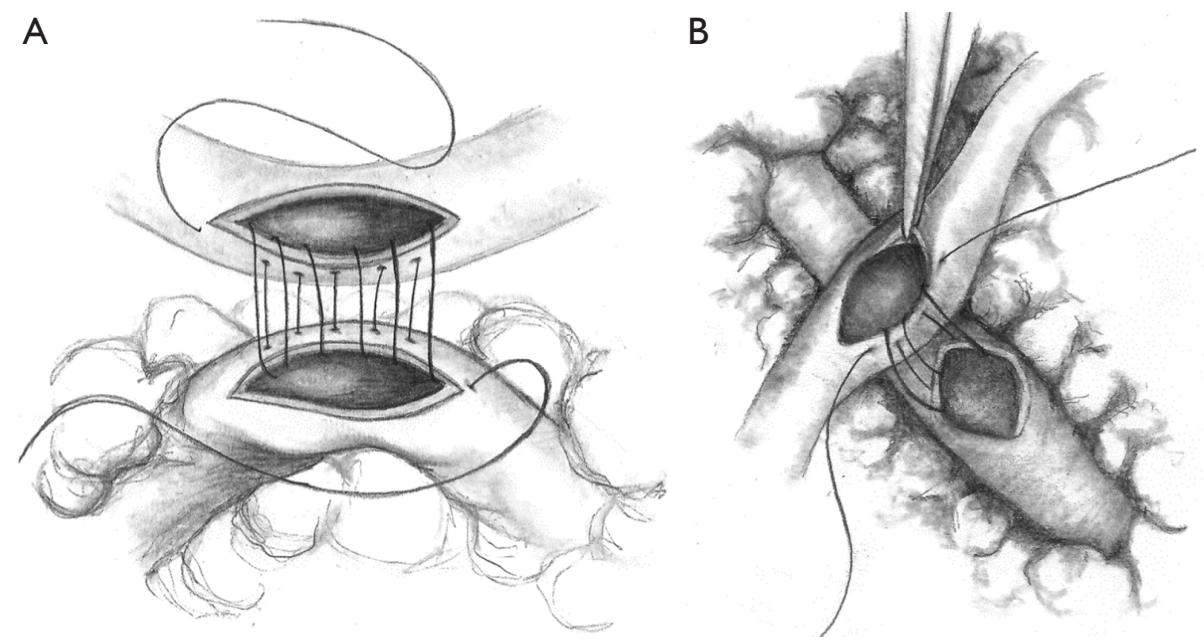

Figure 1 Two types of side to side anastomosis. (A) Latero-lateral anastomosis; (B) diamond shape anastomosis.

ultrasonic Harmonic Scalpel (Ethicon Inc., Cincinnati, Ohio, USA) and demonstrated that the mean effective length of the ITA obtained was approximately $4 \mathrm{~cm}$ longer than that obtained using the conventional thick pedicle harvesting technique (13). They concluded that, in most of the cases, this extra length enables complete revascularization of the anterior and lateral walls using the LITA/RITA associated with sequential grafting, if the heart is not enlarged. They also demonstrated sufficient free flow in both the LITA $(122.2 \pm 44.8 \mathrm{~mL} / \mathrm{min})$ and RITA $(137.7 \pm 51.7 \mathrm{~mL} / \mathrm{min})$, which reduces the likelihood of competitive flow during sequential grafting. Similar data have been reported by Wendler and colleagues (14), who also show significantly higher free flow in skeletonized ITAs compared to pedicled ITAs $(197.2 \pm 66.6$ vs. $147 \pm 70.5 \mathrm{~mL} / \mathrm{min}$, $\mathrm{P}<0.005)$.

With respect to avoiding infection, a post hoc analysis of a recent, large-size, randomized, controlled study, the Arterial Revascularization Trial (ART), showed lower incidence of sternal wound complications in the skeletonized BITA group compared to the pedicled BITA group (15). Additionally, the recent guidelines from the Society of Thoracic Surgeons (STS) support skeletonization when using BITA (COR IIa, LOE B) (16).

\section{Sequential grafting using ITA}

Sequential grafting (Figure $1 A, B$ ) is a very useful technique performed to achieve effective revascularization with only two ITAs. Sequential grafting requires the use of two different anastomotic techniques. A diamond anastomosis is constructed with the conduit perpendicular to the coronary target. A parallel anastomosis is constructed when the conduit is parallel to the coronary target, in either a sideto-side or end-to-side configuration (17). In the diamond anastomosis, the size of the ITA incision must not exceed the diameter of the ITA to avoid a "seagull deformity" of the anastomosis (Figure 2).

Sequential grafting using ITA is technically challenging because of the smaller diameter compared to vein grafts, limited length and the need to appropriately configure the multiple distal anastomoses. Despite these challenges, excellent outcomes have been reported by many groups. A recent propensity-matched study by Ji and colleagues (18) showed comparable graft patency between LITA-diagonalleft anterior descending (LAD) $(99.1 \%$ at the diagonal site, $98.1 \%$ at the LAD site) and LITA-to-LAD (98.2\%) at 27 months. With respect to LITA sequential grafting for the lateral and inferior walls, clinical results are available from studies conducted in Turkey, Japan, and Canada. Bakay and colleagues (19), using patency data from 101 patients who underwent sequential LITA grafting for circumflex coronary artery $(\mathrm{Cx})$ and right coronary artery (RCA) lesions, show that patency rates at 27 months after sequential anastomosis to the circumflex artery and the RCA were $98.0 \%$ and $95.0 \%$, respectively. Ohira and colleagues (17) have analyzed LITA sequential grafting to left circumflex lesions in propensity-matched patients groups (LITA-Cx individual grafting vs. LITA-Cx sequential grafting, $n=147$ ) and illustrated that freedom from target vessel revascularization was $94.6 \%$ in sequential group and $96.3 \%$ in the individual group (log-rank 

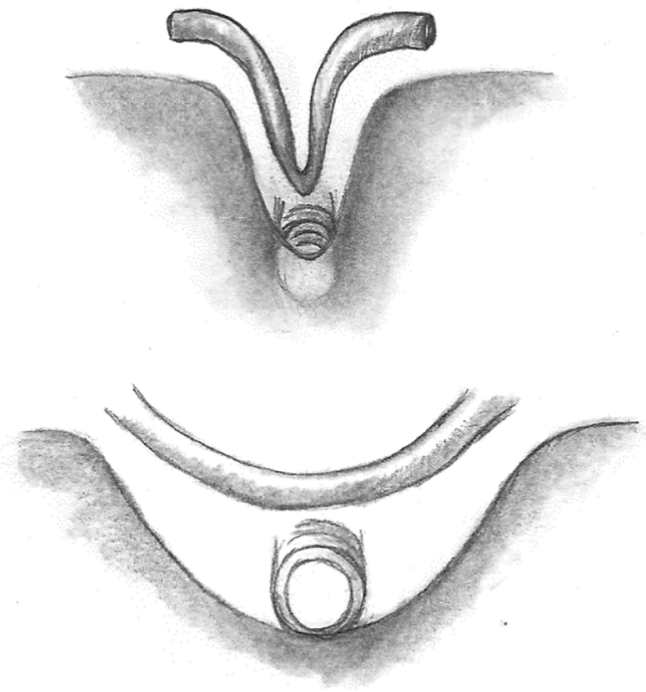

Figure 2 Seagull effect.

$\mathrm{P}=0.645$ ), demonstrating adequate safety of sequential ITA grafting. Glineur et al. demonstrated excellent graft patency of ITA sequential grafting in the randomized trial comparing in situ BITA and BITA-Y grafting. In their trial, they evaluated grafts with systematic followup angiogram, and showed RITA patency up to $94.5 \%$ in BITA-Y grafting group, which were done in sequential grafting at 3 years after the procedure (20). Despite these positive results, previous studies have also identified problems with sequential grafting. The most concerning issues pertain to graft design and function (competitive flow, string sign). The study by Ohira and colleagues (17) demonstrated a better patency of the distal segment of the sequential graft with a diamond anastomosis compared to a parallel anastomosis at the early postoperative period (98.4\% vs. $90.7 \%$, respectively). The reason for this difference is unclear, but factors such as suboptimal graft configuration or inappropriate selection of the target vessels may have influenced patency rates. However, we need to recognize that the patency of ITA is still higher than that of saphenous vein grafts (21).

Nakajima and colleagues (22) have also published longterm angiographic data on sequential grafting to investigate the predictors of competitive flow. In targets where the stenosis was $51-75 \%$, they found that RCA territories, end-to-side anastomosis, and RA composite grafts were all significant predictors of competitive flow. Glineur et al. have reported similar data on graft function using the Y-composite graft (23). Specifically, they found that RITA function improved when it was used on several branches of the circumflex and on tight $(>70 \%)$ stenosis on the first circumflex branch, but was worsened by grafting distal branches of the RCA.

To achieve successful sequential grafting, several factors have to be taken in consideration, such as: coronary anatomy, severity of the coronary lesion, graft configurations and quality, conduit length and type of anastomosis.

\section{In situ BITA grafting}

\section{Techniques of in situ BITA grafting (advantages and disadvantages)}

(I) LITA-to-LAD, RITA-to-Cx (crossing the transverse sinus);

* Advantages:

- RITA is used as an individual graft; there are no graft function issues;

- Safe approach in patients who may require a redo sternotomy;

- LITA reaches the distal LAD in case of calcified mid LAD, which is not graftable and also enables us to perform sequential LAD-Diag.

* Disadvantages:

- The length of the RITA does not always allow performance of this technique without significant tension in the RITA;

- RITA in the transverse sinus only reaches the ramus or first obtuse marginal $(\mathrm{OM})$ and therefore can require a third graft;

- The limited length of the RITA in this configuration often leads to use the very distal end of the RITA, which has been described as more muscular with lower patency.

(II) RITA-to-LAD, LITA-to-Cx.

* Advantages:

- Each ITA is used in situ, and can provide sufficient blood flow to the distal targets;

- Sequential grafting with the LITA can be performed on the lateral myocardial wall.

* Disadvantages:

- The RITA crosses the midline, which significantly increases the risk of graft injury during redo surgery;

- The length of the RITA often does not reach the distal LAD for cases of intra myocardial mid LAD or severe mid LAD calcifications;

- It is very difficult to perform sequential Diag-LAD 
grafting with the RITA used in this configuration;

- The limited length of the RITA in this configuration often requires the use of the very distal end of the RITA, which has been described as more muscular with lower patency;

- There is often the need for a third graft for the distal Cx.

\section{Clinical and angiographic results of in situ BITA grafting}

LITA-to-LAD grafting is the long-standing and proven gold standard in coronary artery surgery. However, the safety and efficacy of RITA to LAD grafting has also been shown. Indeed, Raja et al. (24) reviewed data from 1,667 patients who underwent BITA grafting, and propensity matched them into two cohorts, either RITA-LAD + LITACx $(n=546)$ or LITA-LAD + RITA as a free/composite graft $(n=546)$. The clinical outcomes were compared, and the authors found no difference in the rates of late death or repeat revascularization after an average of 7.8 years. With respect to patency, Fukui et al. (25) analyzed angiographic data on skeletonized RITA that were obtained during the early postoperative period and at 1-year post-procedure. Focusing on in situ RITA, the best patency rate was obtained with a RITA-to-anterior wall graft $(99.4 \%$ in the early postoperative period and $98.4 \%$ at 1-year), while the in situ RITA-to-lateral wall graft also showed good patency $(98.1 \%$ in the early postoperative period and $89.3 \%$ at 1 -year), although it was inferior to the RITA-to-anterior wall graft.

The RITA-to-LAD strategy significantly increases the risk during re-entry and therefore, the grafting strategy has to take into consideration the possible need for a future repeat sternotomy. Data from the Cleveland Clinic (26) show that the rate of an ITA injury during a redo procedure is at least $1.3 \%$, and that once it occurs, the prognosis is poor. Endovascular treatments for aortic valve replacement should decrease this risk in the future. On the contrary, a redo CABG after BITA grafting is expected to be extremely rare because of the excellent long-term graft patency after BITA.

Routine protective RITA measures, such as placing the RITA within the thymus tissue and keeping it away from the posterior table of the sternum during the initial operation, should be performed in all the cases.

\section{Composite BITA graft strategies}

\section{BITA composite techniques}

Composite BITA grafting is a technique that facilitates increased grafting plasticity to the free RITA due to the extra length provided by this configuration. This grafting technique allows revascularization of the entire anterior and lateral myocardial walls without limitation. Depending on the patient's anatomy, the RITA may even reach the distal RCA territory. As described in previous publications $(27,28)$, in this configuration the free RITA is anastomosed to the posterior wall of the LITA using 8-0 polypropylene suture. To revascularize lesions in the $\mathrm{OM}$ or posterior lateral artery (PL), the RITA is anastomosed to the LITA at a 60-degree angle, known as a $\mathrm{Y}$ composite (Figure $3 A$ ). If the ramus intermedius or a diagonal branch is the target, it is preferable to anastomose the RITA to the LITA as a T composite at a 90-degree angle (Figure 3B). In either case, the anastomosis should be made on the dorsal side of the LITA, and it should rest within the pericardium to avoid kinking.

\section{Advantages and disadvantages of the BITA composite strategy}

* Advantages:

- This grafting technique allows revascularization of the entire anterior and lateral myocardial wall without any limitation;

- In cases with an occluded or sub-occluded RCA, this strategy also allows revascularization of the RCA system.

* Disadvantages:

- The integrity of the ITA-to-ITA anastomosis is crucial, and technical issues can completely jeopardize the revascularization;

- The risk of competitive flow significantly increases with the length of the RITA. Therefore, distal coronary targets of the RITA on the distal lateral wall or inferior wall have to be severely narrowed to avoid flow competition.

The greatest benefit of the BITA composite strategy is that it allows complete revascularization without the need for additional conduits and therefore, the need for aortic manipulation during construction of the proximal anastomosis. In addition, in this configuration, the RITA does not cross the midline, which is advantageous in a redo situation. Concerns regarding BITA composite grafting include potential risks of "steal phenomenon" and "competitive flow" from the LITA to the RITA, and the fact that this composite design may not result in adequate flow to the entire coronary system. With respect to the 
A
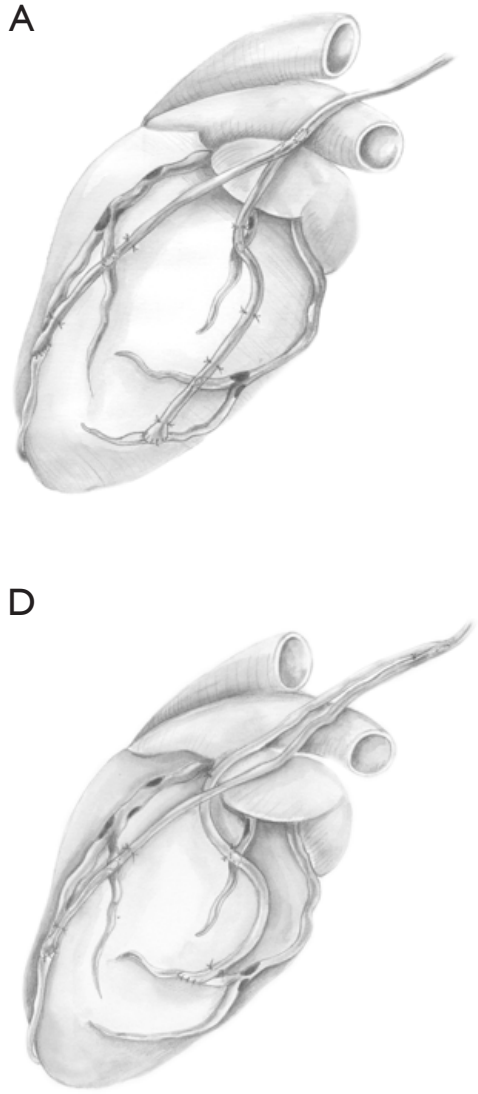

B
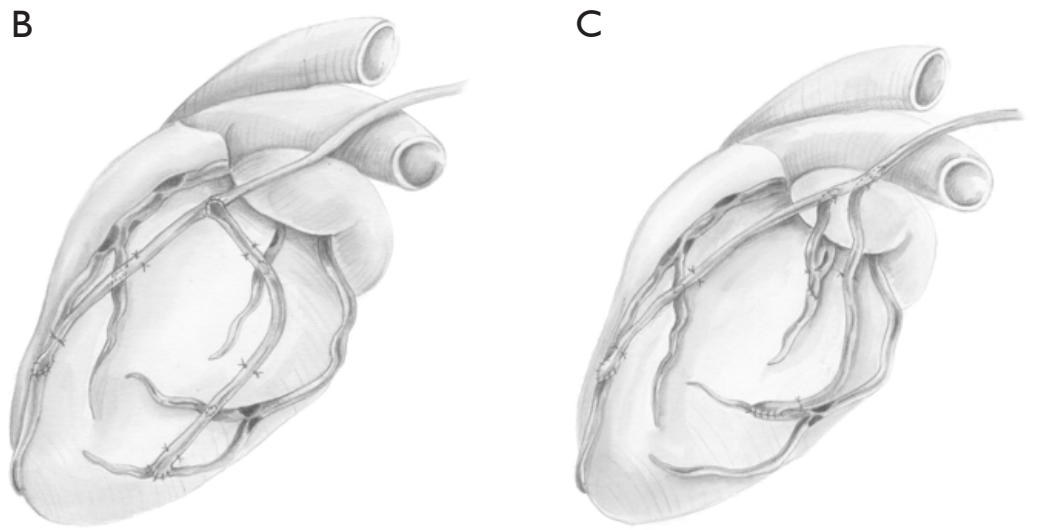

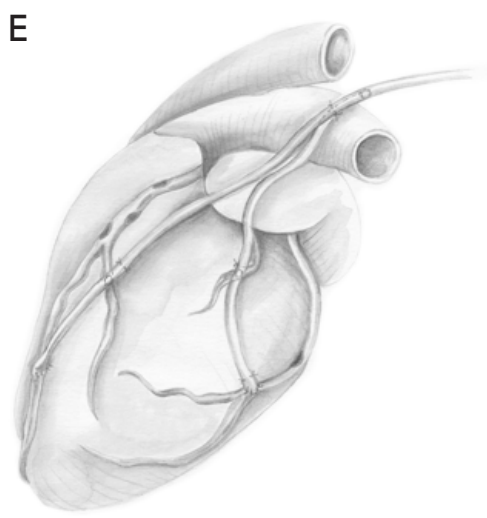

Figure 3 Different types of composite configurations. (A) angulation of the RITA on the intermediate branch is not perpendicular; (B) proximal T anastomoses on the LITA; (C) use of a second small Y-graft; (D) proximal composite anastomose of a free RITA on the LITA very high on the LITA; (E) latero-lateral anastomose on the intermediate branch. From Glineur et al. (23), reprinted with permission. RITA, right internal thoracic artery; LITA, left internal thoracic artery.

steal phenomenon, Glineur et al. have published data on catheter-based fractional flow reserve (FFR) assessment of BITA Y-composite grafts (29), which shows that there was no difference in conductance between the two Y-graft branches during hyperemia, attesting to the safety of this graft configuration. With regard to flow capacity, Sakaguchi et al. have used PET scans to assess the regional myocardial blood flow and coronary flow reserve at 2 weeks after CABG between Y-composite and individual grafts (30). In their study, as the $\mathrm{Y}$-composite graft showed significantly lower flow reserve, they concluded that the Y-composite is not as effective as individual grafting. Not every group came to the same conclusion. Lemma et al. (31) have demonstrated persistence of flow reserve in the area of the Y-graft during an increase in myocardial blood flow induced by atrial pacing. Similarly, Royse et al. (32) have published data supporting the ability of the Y-composite graft, to remarkably increase its free flow through the ITA axis from $99.9 \pm 16$ to $173 \pm 16 \mathrm{~mL} / \mathrm{min}$, when the Y-graft composite was used.

\section{Clinical and angiographic results of BITA composite}

Mid-term and long-term results of BITA composite grafting have been published by many groups $(19,32)$. A recently-published prospective randomized trial by Glineur et al. (20) compared in situ BITA grafting vs. BITA Y-grafting ( $\mathrm{N}=152$ in each group). The authors found no difference in the rates of in-hospital mortality, late survival, stroke, myocardial infarction, or patency of the ITA at 3 years. Despite these early similarities, the BITA-Y grafting group had a lower incidence of major adverse cardiac and cerebrovascular events (MACCE) at 7 years (in situ group; $14 \% \pm 4.5 \%$ vs. BITA-Y group $7.4 \% \pm 3.2 \%$, 
$\mathrm{P}=0.009)$ and lower incidence of revascularization events (in situ $28 v$ s. BITA $11, \mathrm{P}<0.01$ ). The differences in revascularization rate were primarily due to the increased incidence of percutaneous coronary intervention (PCI) to vessels that were not revascularized by ITA grafts in the in situ group.

Results from retrospective studies are also available. Calafiore and colleagues (33) reviewed data from 1,818 patients who had undergone BITA grafting and compared BITA Y with in situ BITA grafting. They found a greater number of anastomoses using ITAs in the BITA Y group (BITA Y vs. in situ, $2.7 \pm 0.9$ vs. $2.2 \pm 0.6, \mathrm{P}<0.01$ ) with comparable survival and event rates at 8 years. The same group recently published 20-year outcomes of BITA Y grafting (34), which showed that the clinical outcomes of BITA grafting were independent of surgical configuration. The authors concluded that $\mathrm{Y}$ grafting increases the plasticity of BITA by increasing the number of distal territories that can be reached with this configuration. Huang and colleagues (35) compared an in situ group versus a Y graft group (all cases were performed using an offpump approach) using propensity-score matched analysis. There were no differences in early, 1-year, and 5-year graft patency rates. Furthermore, freedom from cardiac death, reintervention-free rate and major adverse cardiac-events were similar between the two groups.

In summary, Y composite grafting is a safe and effective strategy which allows complete revascularization of the left coronary system with the best available graft.

\section{Conclusions}

Bilateral ITA grafting is a technique that improves clinical outcomes after CABG, but the debate on which BITA grafting strategy is the best remains unsolved. To maximize the advantages of BITA use, skeletonized ITA harvesting and the adoption of multiple sequential anastomoses are recommended. Composite $\mathrm{Y}$ or $\mathrm{T}$ grafting allows revascularization of the entire left coronary system using both internal thoracic arteries. While composite Y grafting enables revascularization of distal branches of the right coronary system, the degree of target vessel stenosis should be critical to avoid competitive flow and potential graft malfunction. In situ BITA grafting is also a very efficient strategy to revascularize the left coronary system.

The question is not which BITA grafting technique is better, but rather which technique is most likely to allow complete revascularization with arterial targets for a specific patient. The choice of BITA grafting strategy should be based on the coronary anatomy and patient characteristics in order to maximize the completeness of revascularization and minimize the long term MACCE.

\section{Acknowledgements}

None.

\section{Footnote}

Conflicts of Interest: The authors have no conflicts of interest to declare.

\section{References}

1. Märkl B, Raab S, Arnholdt H, et al. Morphological and histopathological comparison of left and right internal thoracic artery with implications on their use for coronary surgery. Interact Cardiovasc Thorac Surg 2003;2:73-6.

2. Ferrari G, Quackenbush J, Strobeck J, et al. Comparative genome-wide transcriptional analysis of human left and right internal mammary arteries. Genomics 2014;104:36-44.

3. Yi G, Shine B, Rehman SM, et al. Effect of bilateral internal mammary grafts on long-term survival: a metaanalysis approach. Circulation 2014;130:539-45.

4. Grau JB, Ferrari G, Mak AW, et al. A propensity matched analysis of bilateral internal mammary artery grafting at 17-year follow-up: validation of a contemporary surgical experience. Eur J Cardiothorac Surg 2012;41:770-5.

5. Glineur D, D'hoore W, Price J, et al. Survival benefit of multiple arterial grafting in a 25 -year single-institutional experience: the importance of the third arterial graft. Eur J Cardiothorac Surg 2012;42:284-90.

6. Lytle BW. Prolonging patency-choosing coronary bypass grafts. N Engl J Med 2004;351:2262-4.

7. Kieser TM, Rose MS, Aluthman U, et al. Quicker yet safe: skeltonization of 1640 internal mammry arteries with harmonic technology in 965 patients. Eur J Cardiothorac Surg 2014;45:e142-50.

8. Wendler O, Hennen B, Demertzis S, et al. Complete arterial revascularization in multivessel coronary artery disease with 2 conduits (skeletonized grafts and T grafts). Circulation 2000;102:III79-83.

9. Peterson MD, Borger MA, Rao V, et al. Skeletonization of bilateral internal thoracic artery grafts lowers the risk of sternal infection in patients with diabetes. J Thorac 
Cardiovasc Surg 2003;126:1314-9.

10. Gaudino M, Toesca A, Nori SL, et al. Effect of skeltonization of the internal thoracic artery on vessel wall integrity. Ann Thorac Surg 1999;68:1623-7.

11. Yoshikai M, Ito T, Kamohara K, et al. Endothelial integrity of ultrasonically skeletonized internal thoracic artery: morphological analysis with scanning electron microscopy. Eur J Cardiothorac Surg 2004;25:208-11.

12. Boodhwani M, Lam BK, Nathan HJ, et al. Skeltonized internal thoracic artery harvest reduces pain and dysesthesia and improves sternal perfusion after coronary artery bypass surgery: a randomized, double-blind, within patient comparison. Circulation 2006;114:766-73.

13. Higami T, Yamashita T, Nohara H, et al. Early results of coronary grafting using ultrasonically skeletonized internal thoracic arteries. Ann Thorac Surg 2001;71:1224-8.

14. Wendler O, Tscholl D, Huang Q, et al. Free flow capacity of skeletonized versus pedicled internal thoracic artery grafts in coronary artery bypass grafts. Eur J Cardiothorac Surg 1999; 15:247-50.

15. Benedetto U, Altman DG, Gerry S, et al. Pedicled and skeletonized single and bilateral internal thoracic artery grafts and the incidence of sternal wound complications: Insights from the Arterial Revascularization Trial. J Thorac Cardiovasc Surg 2016:152:270-6.

16. Aldea GS, Bakaeen FG, Pal J, et al. The Society of Thoracic Surgeons Clinical Practice Guidelines on Arterial Conduits for Coronary Artery Bypass Grafting. Ann Thorac Surg 2016;101:801-9.

17. Ohira S, Doi K, Okawa K, et al. Safety and Efficacy of Sequential Left Internal Thoracic Artery Grafting to Left Circumflex Area. Ann Thorac Surg 2016;102:766-73.

18. Ji Q, Shi Y, Xia L, et al. Revascularization of Left Coronary System Using a Skeltonized Left Internal Mammary Artery-Sequential vs. Separate Grafting. Circ J 2017;82:102-9.

19. Bakay C, Onan B, Korkmaz AA, et al. Sequential in-situ left internal thoracic artery to the circumflex and right coronary artery areas. Ann Thorac Surg 2013;95:63-70.

20. Glineur D, Boodhwani M, Hanet C, et al. Bilateral Internal Thoracic Artery Configuration for Coronary Artery Bypass Surgery: A Prospective Randomized Trial. Circ Cardiovasc Interv 2016;9. doi: 10.1161/ CIRCINTERVENTIONS.115.003518.

21. Motwani JG, Topol EJ. Aortocoronary saphenous vein graft disease: pathogenesis, predisposition, and prevention. Circulation 1998;97:916-31.
22. Nakajima H, Kobayashi J, Toda K, et al. A 10-year angiographic follow-up of competitive flow in sequential and composite arterial grafts. Eur J Cardiothorac Surg 2011;40:399-404.

23. Glineur D, Hanet C, D'hoore W et al. Causes of non-functioning right internal mammary used in a Y-graft configuration: insight from a 6-month systematic angiographic trial. Eur J Cardiothorac Surg 2009;36:129-35.

24. Raja SG, Benedetto U, Husain M, et al. Does grafting of the anterior descending artery with the in-situ right internal thoracic artery have an impact on late outcomes in the context of bilateral internal thoracic artery usage? J Thorac Cardiovasc Surg 2014;148:1275-81.

25. Fukui T, Tabata M, Manabe S, et al. Angiographic outcomes of right internal thoracic artery grafts in-situ or as free grafts in coronary artery bypass grafting. J Thorac Cardiovasc Surg 2010;139:868-73.

26. Roselli EE, Petterson GB, Blackstone EH, et al. Adverse events during reoperative cardiac surgery: frequency, characterization, and rescue. J Thorac Cardiovasc Surg 2008;135:316-23.

27. Glineur D, Papadatos S, Grau JB, et al. Complete myocardial revascularization using only bilateral internal thoracic arteries provides a low-risk and durable 10-year clinical outcome. Eur J Cardiothorac Surg 2016;50:735-41.

28. Robinson BM, Paterson HS, Naidoo R, et al. Bilateral Internal Thoracic Artery Composite Y Grafts: Analysis of 464 Angiograms in 296 Patients. Ann Thorac Surg 2016;101:974-80.

29. Glineur D, Noirhomme P, Reisch J, et al. Resistance to flow of arterial Y grafts 6 months after coronary artery bypass surgery. Circulation 2005;112:I281-5.

30. Sakaguchi G, Tadamura E, Ohnaka M, et al. Composite arterial Y graft has less coronary flow reserve than independent grafts. Ann Thorac Surg 2002;74:493-6.

31. Lemma M, Mangimi A, Gelpi G, et al. Effect of heart rate of phasic Y-graft blood flow and flow reserve in patients with complete arterial myocardial revascularization: an intravascular Doppler catheter study. Eur J Cardiothorac Surg 2003;24:81-5.

32. Royse AG, Royse CF, Groves KL, et al. Blood flow in composite arterial graft and effect of native coronary flow. Ann Thorac Surg 1999;68:1619-22.

33. Calafiore AM, Contini M, Vitolla G, et al. Bilateral internal thoracic artery grafting: long-term clinical and angiographic results of in-situ versus $\mathrm{Y}$ grafts. J Thorac 
Cardiovasc Surg 2000;120:990-6.

34. Di Mauro M, Iaco AL, Allam A, et al. Bilateral internal mammary artery grafting: in-situ versus $\mathrm{Y}$-graft.

Similar 20-year outcome. Eur J Cardiothorac Surg 2016;50:729-34.

Cite this article as: Kawajiri H, Grau JB, Fortier JH, Glineur D. Bilateral internal thoracic artery grafting: in situ or composite? Ann Cardiothorac Surg 2018;7(5):673-680. doi: 10.21037/acs.2018.05.16
35. Hwang HY, Kim JS, Cho KR, et al. Bilateral Internal Thoracic Artery In-situ Versus Y-Composite Graftings: Five-year Angiographic Patency and Long-Term Clinical Outcomes. Ann Thorac Surg 2011;92:579-85. 